\title{
Research on Self-Operated Business Risk Control of Futures Company
}

\author{
Jianfei Leng1,2, Qiaoyun Ye2, Guorong Jia² \\ ${ }^{1}$ Management School, Fudan University, Shanghai, China \\ ${ }^{2}$ Business School, Hohai University, Nanjing, China \\ Email: 1140980017@qq.com
}

Received 30 March 2015; accepted 3 May 2015; published 7 May 2015

Copyright (C) 2015 by authors and Scientific Research Publishing Inc.

This work is licensed under the Creative Commons Attribution International License (CC BY). http://creativecommons.org/licenses/by/4.0/

(c) (i) Open Access

\begin{abstract}
Under the new development situation of China's futures industry, this paper studies on the selfemployed business and its risk control of Futures Company. It analyzes the risks that may be encountered in the self-running business, establishes and improves the process of risk control of Futures Company proprietary business in China, which really plays the function of risk control, making it become the profit breakthrough of the Futures Company.
\end{abstract}

\section{Keywords}

\section{Futures Companies, Risk Control, Self-Operated Business}

\section{Introduction}

China Securities Regulatory Commission announced the "Futures Company asset management business pilot measures" on July 31, 2012, it means that the innovation business has become an important breakthrough in China's Futures Company to change the current situation. Futures Company proprietary business is the most can manifest the value of their own business and create core competitiveness in all innovation business of Futures Company. And at the same time, the risk Futures Company proprietary business faces is also the biggest.

In the process of rapid development in Futures Company, it will inevitably enter the field of innovation business, especially the self-operated business that may bring greater benefits for the futures company. Even it can participate in the international market futures proprietary business in the future. It is a relatively new research topic on how to grasp the historical opportunity and control the risk in the smallest range at the current futures industry. 


\section{Literature Review}

On the risk management and control side, Khindanova and Schwartz (1999) [1] advocate that we can bring price, preference and VaR risk management together. They put forward the concept of comprehensive risk management of financial intermediaries. Gibson (1998) [2] thinks that the risk management system will become more centralized with the progress of information technology. Polsky (1997) [3] points out that the investment manager should not only have the benchmark index, but also have the benchmark risk index from the perspective of investment managers.

Christofferse \& Errunza (2000) [4] point out that it is crucially important to establish a complete department structure and control process in self-employed business risk control, in order to answer for the operation of various assets control.

Compared with foreign counterparts, domestic Futures Company is characterized by small scale and single business, therefore domestic research on Futures Company risk management is still in the exploratory stage. From the current literature, most domestic scholars carry out a theoretical and empirical study on securities companies risk management.

Deng Shaoling (2002) [5] studies the basic procedure and method of securities companies risk management in China. He analyzes the risk management ideas of securities companies. Chen Yunxian (2002) [6] draws on the experience of foreign risk management, combined with the current situation of domestic securities companies risk management. He puts forward the "risk-benefit correspondence theory" of risk management. Zhu Yumei (2003) [7] points out that domestic security companies risk management should start with the construction of internal control system. He thinks that the improvement of the internal control system is the foundation of risk management. Xu Pingcai (2004) [8] argues that because of government intervention in the market, the formulation of the policy is lack of continuity. He suggests we should conduct risk management form three aspects: law, market and management. He Junguang (2006) [9] uses Logistic regression method to establish a risk warning model according to five index, asset liability ratio, current debt ratio, current assets ratio, liquidity ratio and brokerage business ratio. Dai Zhihui (2007) [10] analyzes the risk and investment risk measurement of the main business in securities companies on the journal "The prediction and control of stock investment risk in futures companies”.

\section{Risk and Risk Management Theory}

\subsection{The Concept of Risk}

At present, the research about risk basically reached a consensus on this: "risk refers to the possibility and uncertainty of losses, and there is still controversy over whether the uncertainty can be measured or not.”

This paper argues that: 1) Risk is the possibility and uncertainty of losses. 2) The measurement of risk is the biggest difficulties of risk management, how to accurately measure the risk is one of the biggest challenge faced with sociology, finance and management. 3) Different people take different attitude toward risk, and it can be divided into three types: risk aversion, risk preferences and risk neutral.

\subsection{Concepts of Risk Management}

Risk management is actually refers to a series of management behavior conducted by the action subject to change their risk status, it is a process of controlling risk, including risk identification, risk measurement, risk management strategy, risk control and effect evaluation.

Among this, risk measurement and risk control is the key and foundation in the whole risk management process. The basic process of risk management can refer to Figure 1.

\section{Risk Analysis of the Future Company's Self-Operated Business}

The risk of proprietary business in Futures Companies refers to the extent of the damage or the possibility of not arriving at the expected rate of return when they engaged in self-operated business investment. According to the experience of proprietary business risk control in foreign Futures Companies, we summarized the main characteristics of risk as follows: 


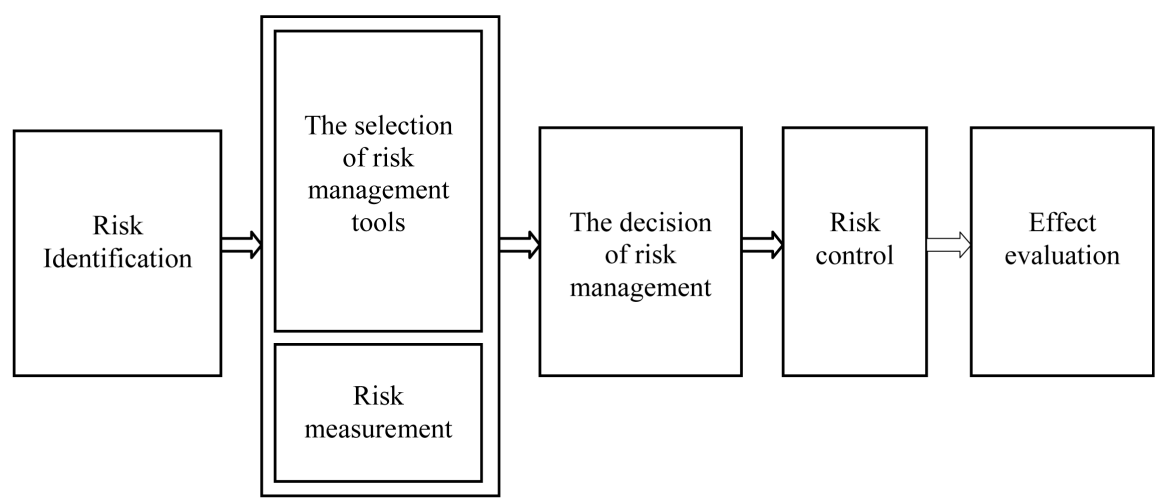

Figure 1. The basic process of risk management.

\subsection{Objective Existence}

The risk factors of futures market is objectively exist, triggering risk accidents through its accumulation in time and quantity and thus affecting the price fluctuation of the futures market, which caused a deviation between the actual return and expected return of investors. So, the risk of future investment objectively exists, and it does not transfer with subject will.

\subsection{Strong Volatility}

The major different between futures investment and general merchandise market is that the futures investment consist of investors and speculators. In the daily operation of futures investment, hedging and speculation are concomitant and are difficult to distinguish their boundaries, in some cases, they can be transformed. Speculative capital is mainly used to win the profit of price margin through short-term price fluctuation, so when the speculation turned to excessive speculation or even crazy speculation, there are still market risks, especially in futures market where leverage effect is strong, the price would be more sensitive.

\subsection{High Risk}

Futures investment faced with the vast number of direct investors, the distribution is wide. Therefore, futures investment is linked to the interests of thousands of households, once the market risk occurred, it can easily lead to social problems. It brings excessive speculation when the market price fluctuates violently. Investors tend to suffer heavy losses when chasing a large quilt. In addition, with the further expansion of the inherent risks in the futures market, it will lead to financial and economic crisis, causing serious damage to the country's society, economic, and political stability.

\subsection{Weak Controllability}

Risk factors in the futures market are not controllable by the future investment itself. In addition, various nonstandard and illegal behaviors emerge in an endless stream due to the limitation of market supervision ability and industry self-discipline. There is still a certain time lag finding, punishing and correcting these illegal behaviors, which further increasing the difficulty of market risk control.

\subsection{Strong Outburst}

The commodity futures is sensitive to various policies, information such as economic conditions, political situation, science and technology, and the producing of these factors is uncertain, the risk of futures investment is also uncertain, thus the outburst of the risk is very strong.

\section{Risk Control of Self-Operated Business in Future Company}

We have no Futures Company proprietary business in our country at present, so we have no ready-made experience for reference. In the process of constructing our own risk control of Futures Company proprietary busi- 
ness, we have to draw on the successful experience of foreign future companies on the hand, and on the other hand, we also have to combine the risk control process with our special circumstances faced with China's Futures Company.

The entire risk control activities of Futures Company proprietary business can be divided into three aspects: control before risk had happened, control when the risk had happened, control after risk had happened according to the analysis of the international COSO risk management and control standards with references to Yu Liring's (2004) [11], Xiao Xinhua's (2010) [12] research achievements. The content of "control before risk had happened" is the construction and improvement of the risk control system and control process of internal control in the company in order to create a good corporate culture and awareness of risk management, which can lay a good foundation for the follow-up control activities; "control when the risk had happened" are mainly focused on early-warning system of self-operated risk and a continue monitor and correct on control activities; "control after the risk had happened" refers to the measures, such as transfer of risk, disposal of risk and remedy of risk, taken after risk had happened.

\subsection{Control before the Risk Had Happened}

1) The establishment of a suitable organizational structure of risk control

Appropriate organization structure of risk control determines the control process and behavior of operating risk control in future company, which decides the decision and execution of self-employed business risk control. This paper designed the following risk control organization structure drawing on the organization platform architecture of futures company internal risk management based on Li Jinan (2005)'s [13] research. The specific organization structure of risk control was shown in Figure 2. The specific functions of each department are as follows:

a) The finance and audit committee are generally made up of the outside directors, they authorized the risk monitoring committee to formulate the company's risk management policy.

b) The highest decision-making executive committee was in charge of the company's various business risk tolerance, and was also responsible for the approval of the company's major risk control decisions, including concerning important risk policy submitted by risk monitoring committee.

c) Risk monitoring committee generally consists of risk control manager and senior business personnel, the head of the risk management committee generally served as the head of this committee. Risk monitoring committee is responsible for the recognition, measurement and monitoring of the risk concerning business department. At the same time, the committee should also assist the highest decision-making executive committee to formulate suitable tolerance of each business risk, and report regularly to the audit committee and the highest decision-making executive committee about the risk management matter.

d) The risk management committee is a special department responsible for the risk management process. The head of the commission reports directly to the finance director, the committee is also served as the head of risk policy group and risk monitoring committee as well as the member of the highest decision-making executive committee. The risk management committee is in charge of the company's credit risk and market risk. The risk

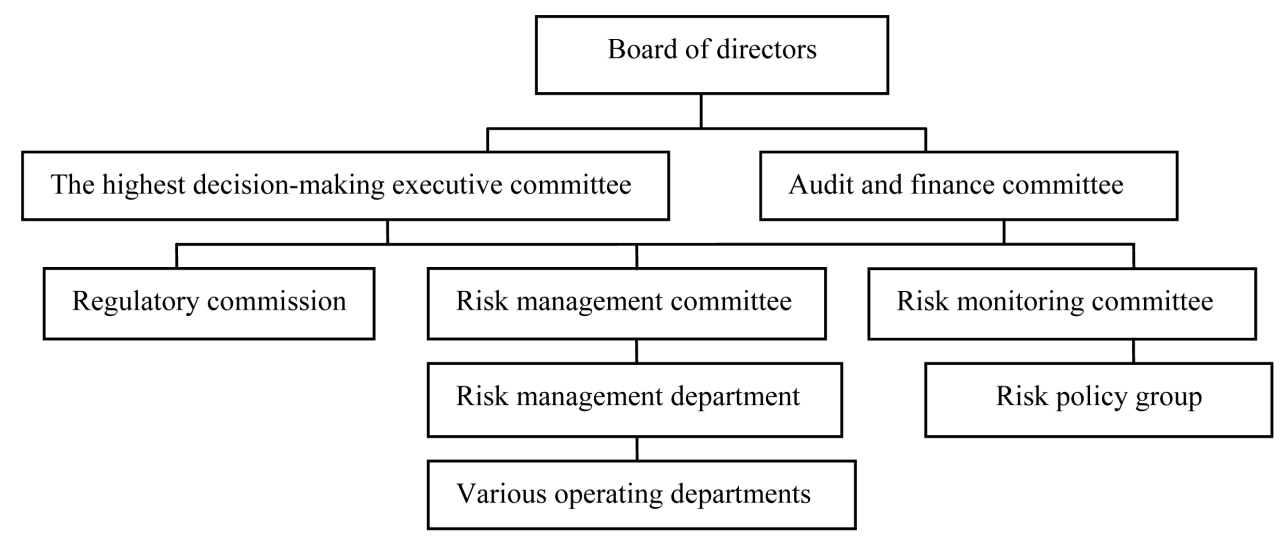

Figure 2. Organization structure design of risk control. 
management committee must familiarly grasp the risk of a variety of investment portfolio and develop related systems and risk tool to perform the corresponding risk control.

e) The company also should be equipped with various control committees in order to formulate policy and review the business, ensuring that the innovation of existing business and new business does not exceed the risk tolerance made by the company. These committees generally include new product examination and review committee, credit policy committee, especially trade review Committee, etc.

f) Risk policy group is a member of risk monitoring committee, which is made up of risk control managers, and one from risk monitoring committee is running it. The group is responsible for examining and reviewing matters related various risk in proprietary business, and at the same time reporting to the risk monitoring committee.

g) The risk management department is responsible for the specific implementation and operation of various risk management policies. It monitored as well as controlled the risk under the direct guidance of risk management committee of the company, the business of real time monitoring and control.

2) Construct systematic risk control system

Constructing systematic risk control system can provide reasonable assurance for internal risk control of the company. Establishing and perfecting the risk control system is the core of constructing risk management of futures company proprietary business in china. We regulate the self-employed business through the formulation of rules and regulations to implement the business behavior; we formulate and implement the scalping management rules, operator management measures, allocation system of proprietary fund, proprietary investment decision and risk control measures, administration regulations of proprietary account etc. to effectively prevent and avoid various losses causing by man-made irrational behavior and wrong operation., which can increase the income of self-employed business and reduce the risk of the transaction.

3) Strict isolation between business transaction and proprietary business

No strict separation between self-employed business and proprietary business leading to heavy losses. According to the successful experience of foreign futures company, business transaction and proprietary business must maintain absolute independence with important business information. So-called important information refers to the importance that enough to make investors decided to sell or not and other investment activities. It concludes two aspects in establishing a strict separation system between business sanction and proprietary business:

a) Restrictions on capital flows. Not damaging the company's sound management is the prerequisite for capital flowing between brokerage and proprietary business. The funds used by proprietary business must belong to the future company or debt financing in the name of the company.

b) Restrictions on information flow. In order to prevent the harmful information flow, it is necessary to set up a "separation barrier" between brokerage business and self-operated business.

4) Construct organizational culture of risk control and cultivate consciousness of risk control

Future company is an intelligence-intensive enterprise, the risk and profit depends on the consciousness and behavior of all staff to a great extent. Creating a good culture of risk control inside the company and fully strengthening the staff's awareness of risk management is a very important part of risk control process. The specific means and methods are as follows:

a) Improving the risk management system, and often organizing to learn and discuss, which deepen the understanding of risk management among staff.

b) Strengthen the training of risk management, Training the staff to make the staff familiar with various key points of risk, risk management process and the operation and control of risk management software. Not only to make employees remain highly vigilant of risk management consciousness, and also make the employees can effectively prevent and avoid the risk before it had happened, control and handle the risk after the appearance of risk.

c) Establishing mutual supervision system between staffs. Some risk is caused by intentional act of the employee and also a lot of risk produced by unconscious behavior, so it is very necessary to strengthen mutual supervision system between company members.

d) Establishing reward and punishment system of risk management. For example, to reward those who offer practical suggestions on risk management or those who performs well in the process of risk control. Those who bring loss to the company just because of their negligent act or deliberate behavior should be punished severely. Only in this way can all staff take risk control as their own work, and it also can really strengthen the intensity 
and effect of risk management.

\subsection{Control in the Process of Risk}

1) Establishing effective early risk warning mechanism

Constructing perfect early risk warning system to prevent and avoid risk. The main content of the early risk warning system should include: always pay attention to capital adequacy ratio of futures holding company; the indexation of risk management; measure the risk through the risk management technique; assess the sensitivity and market risk of situation changes in market through risk management tool, and then to take targeted measures to prevent risk. In this paper, we designed the specific early risk warning mechanism based on Xiao Xinhua (2010)' studies, as shown in Figure 3.

2) Establishing a real-time monitoring system with the combination of internal audit, audit mechanism and external supervision

The chief risk officer of the Futures Company and internal audit as well as the audit department carried out the supervision and inspection regularly or irregularly on the company's proprietary business, so as to find if there exist irregularities or potential risks. External supervision department took on-site inspection or irregular off-site inspection of related business including the proprietary business in order to find hidden risk. Especially the working reports and papers of chief risk officer and working reports and papers of supervision department should make each other real. This help to judge the level of the proprietary business risk objectively, which would help to discover the risk in time and urge the related departments to take measures timely.

\subsection{Control after the Risk Had Happened}

1) Transfer of the risk

The transfer of the risk means pass on losses or consequences related to the losses to other individuals or companies consciously in order to avoid undertaking risk losses. Transfer the risk of futures proprietary business can be realized through some effective ways. For example, insure your risk, which can transfer part or all of the risk to the insurance company; make the riskier futures investment entrust to a special institution to carry out; transfer the risk losses to others through the form of contract; horizontally transfer the risk through various forms of economic union.

2) Compensation mechanisms of self-operated risk

The Futures Company make up for the losses through the internal financing and assets allocation. The specific handling methods are as follows:

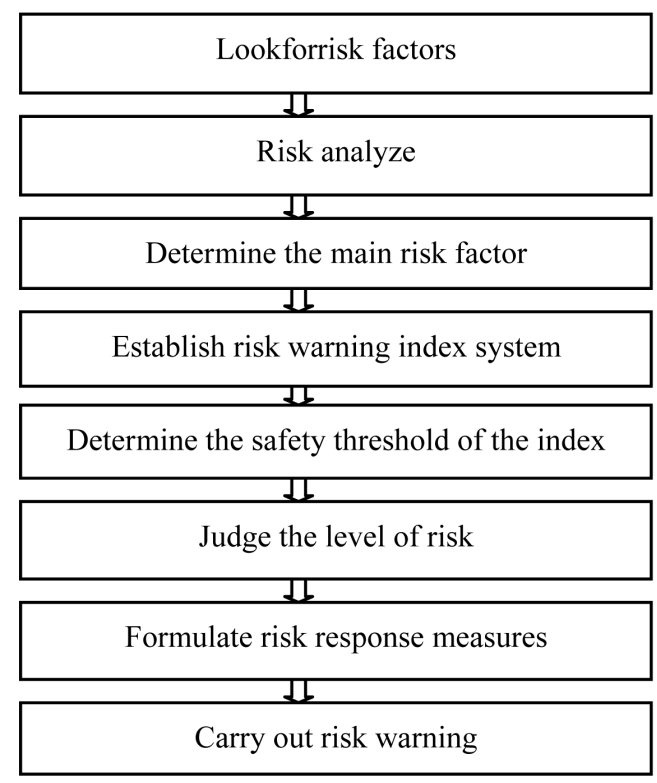

Figure 3. Risk pre-warning mechanism. 
a) The losses count as the operating cost

The self-operated business aims at the pursuit of price margin of futures, so it is inevitable to suffer risk and loss in the process of trading. Therefore, it must generally establish a certain preparation and limitation of risk bearing based on risk preference criteria. This method count a number of contingent risks as the overall cost of proprietary business, so as to use the expenses to pay for the loss after the risk had happened.

b) The establishment of contingency fund

A special contingency fund could be established to compensate for the loss taking from risks. To extract a special compensation fund from the profits in proportion after the self-operated investment entering return period to ensure that the loss can be compensated.

c) Arrange emergency loan

When the contingent fund raised by internal capital insufficient to compensate for the loss, then it can be compensated by external borrowing. The establishment of an effective compensation mechanism can make the futures proprietary business losses not to influence the development of other businesses, which effectively prevent the spread of the risk of self-employed business.

3) The improvement and optimization of risk control process

Companies can set up a special team of investigating risk when the risk had happened. The investigation team carried out careful and overall investigation about the causes of risk, identifying whether the risk is systematic risk or not. Normally, the occurrence of unsystematic risk is necessarily due to imperfect and unreasonable process of risk control. The risk manager should review the whole process of risk control and find out the possible causes of unsystematic risk. Then raising the rectification scheme and carrying out the scheme with the approval of the senior leaders. Optimizing and perfecting the whole process of risk control to reduce losses caused by unsystematic risk.

\section{Conclusion}

This paper mainly studied the problem related to Futures Company proprietary business in China. It offered good theoretical support and practical framework to effectively carry out the self-operated business in the future by rounded analysis and discuss. The research theoretically analyzed the risk management, risk features and risk control, putting forward the basic idea and the specific methods of proprietary business in Chinese futures market.

\section{Funding}

Research projects on Philosophical Society Science of Education Department in Jiangsu Province (Project Number: 2012SJD790025).

\section{References}

[1] Khindanova, R. and Schwartz (1999) Theory of Perceiving Risk and Attractiveness Organ. Behavior and Human Decision Process, 92-98.

[2] Gibson (1998) Initial Public Offerings and Underwriting Reputation. Journal of Finance, 245-268.

[3] Polsky (1997) Factor Affecting Investment Bank Initial Public Offering Market Share. Journal of Financial Economics, 123-135.

[4] Christoffersen, P.F. and Errunza, V.R. (2002) Towards a Global Financial Architecture: Capital Mobility and Risk Management. Emerging Market Review, 2-19.

[5] Deng, S.L., Dai, G.Y. and Wang, Z.C. (2002) Security Institution’ Risk Management. East China Economic Administration, 60-62.

[6] Chen, Y.X. (2002) Correspondence Relation between Risk and Return. Peking University Press, Beijing.

[7] Zhu, Y.M. (2003) Risk Management and Risk Control of Security Companies. South Finance, 28-30.

[8] Xu, P.C. (2004) Discuss about the Risk and Prevention of Self-Operated Business Insecurity Industry. Economy and Management, 45-47.

[9] He, J.G. (2002) Security Companies in Our Country. Chongqing University, Chongqing.

[10] Dai, Z.H. (2007) The Forecast and Control of Stock Investment Risk in Security Companies. Northwest University, Xi'an, 3. 
[11] Yu, L.R. (2004) The Research on Risk Control of Futures Market in China. Fudan University, Shanghai.

[12] Xiao, X.H. (2010) The Research on Proprietary Business Risk Management of Securities Companies. Central South University, Changsha.

[13] Li, J.G. (2005) The Research on Risk Management of Futures Company. Agricultural University of Nanjing, Nanjing. 